\title{
DEVELOPMENT AND VALIDATION OF UV-VIS SPECTROSCOPIC METHOD OF ASSAY OF CARBAMAZEPINE IN MICROPARTICLES
}

\author{
SAEID MEZAIL MAWAZIa,d, HAZRINA A. B. HADIa, SINAN MOHAMMED ABDULLAH AL-MAHMOOD ${ }^{\mathrm{b}}$, ABD \\ ALMONEM DOOLAANEA ${ }^{\mathrm{a}, \mathrm{c}^{*}}$
}

aDepartment of Pharmaceutical Technology, Kulliyyah of Pharmacy, International Islamic University Malaysia, Kuantan Campus,

Malaysia, bDepartment of Basic Medical Science, Kulliyyah of Nursing, International Islamic University Malaysia, Kuantan Campus, Malaysia, 'IKOP Sdn Bhd, Kulliyyah of Pharmacy, International Islamic University Malaysia, dSchool of Pharmacy, PICOMS International University College, Batu Muda, Batu Caves, Kuala Lumpur, Malaysia

Email: abdalmonemdoolaanea@yahoo.com

Received: 26 Mar 2018, Revised and Accepted: 19 Nov 2018

\section{ABSTRACT}

Objective: This study aimed to develop a new, rapid, robust, effective, inexpensive, and accurate UV-Vis method for the quantification analysis of carbamazepine (CBZ) in the carbamazepine-loaded microparticles.

Methods: CBZ was encapsulated in ethyl cellulose microparticles by a solvent evaporation method using polyvinyl alcohol (PVA) as a stabilizer Methanol was used to dissolve CBZ followed by dilution with distilled water as diluent. CBZ drug, excipients, and microparticles were subjected to specificity, solution stability, linearity, precision and accuracy to confirm and ensure the validity of this method.

Results: The results showed no interference from the excipients in the selected wavelength $286 \mathrm{~nm}$. It was exhibited linearity in the range 2-12 $\mu \mathrm{g} / \mathrm{ml}$ with $\mathrm{R}^{2}=0.9992$. CBZ solution was stable during $24 \mathrm{~h}$. Accuracy and precision were within the accepted limits $(100 \pm 2 \%)$. All results were in accordance to the ICH-Q2 guideline.

Conclusion: As a conclusion, CBZ could be quantified from loaded EC microparticles using UV-Vis spectrophotometer at $286 \mathrm{~nm}$. Therefore, this method can be used for the quantification analysis of CBZ in CBZ-loaded microparticles can be utilized also as an alternative method to calculate CBZ in different dosage forms.

Keywords: Carbamazepine, Microparticles, Method validation, UV-Vis, Spectrophotometer

(C) 2019 The Authors. Published by Innovare Academic Sciences Pvt Ltd. This is an open access article under the CC BY license (http://creativecommons.org/licenses/by/4.0/) DOI: http://dx.doi.org/10.22159/ijap.2019v11i1.26256

\section{INTRODUCTION}

Ultraviolet-visible (UV-vis) spectrophotometry is one of the most frequently used techniques in the pharmaceutical analysis. The major law which ruled the spectrophotometric quantitative analysis is Beer-Lambert law [1-3]. It states that when a beam of light is passed through a transparent cell containing a solution of an absorbing substance, reduction of the intensity of light may occur and mathematically can be expressed in Eqn. 1.

$$
\mathrm{A}=\mathrm{a} \cdot \mathrm{b} \cdot \mathrm{c} \text { Eqn. } 1
$$

Where $\mathrm{A}$ is the absorbance (optical density), a is the absorptivity or extinction coefficient, $b$ is the path length of radiation over $a$ sample $(\mathrm{cm})$, and $\mathrm{c}$ is a concentration of solute (substance) in solution [4-7].

Carbamazepine (CBZ) is an anticonvulsant medication used for the treatment of seizures, bipolar disorder, neuropathic pain, neuralgia, and trigeminal. It works by diminishing nerve impulses that reason seizures and agony [8]. The available CBZ dosage forms in the market are chewable tablets, suspension, sustained release capsules and sustained-releasetablets [9].

Several analysis methods were used to quantify CBZ in pharmaceutical dosage forms. By using HPLC-UV [10, 11]. CBZ was quantified in the plasma using mobile phase of water, methanol, and acetonitrile (ACN) using HPLC chromatographic method [12]. UV-vis analysis method was used for dissolution test of CBZ sustainedrelease tablets in the pharmacopoeia at the wavelength maxima 283 $\mathrm{nm}$ with water as medium [13].

The current study was done to validate the spectroscopic method for quantification of CBZ in EC microparticles. The UV-Vis spectroscopy validation method for CBZ is an ecessary method to ensure the proper characterization of CBZ-loaded microparticles especially for the encapsulation efficiency and release profile.

\section{MATERIALS AND METHODS}

Carbamazepine (CBZ) was purchased from Anuja Healthcare Limited (Punjab, India). Ethyl cellulose (EC) polymer was purchased from Dow Chemicals (Louisiana, Greensburg, USA). Polyvinyl alcohol (PVA) was from Merck (Hohenbrunn, Germany). Solvents used in the analysis were from Merck (Hohenbrunn, Germany).

\section{Preparation of carbamazepine microparticles}

Carbamazepine (CBZ) loaded microparticles were prepared by a solvent evaporation method [14] using ethyl cellulose (EC) as a polymer, and stabilized by utilizing polyvinyl alcohol (PVA). Dichloromethane (DCM) and ethyl acetate (EA) were used here as organic phase solvents. EC was dissolved in a mixture of DCM: EA (9:1) ratio then $0.2 \mathrm{~g}$ of CBZ was added to form the organic phase. The aqueous phase was prepared by using $0.5 \%$ PVA solution. The organic phase was added to the aqueous phase and mixed using a mechanical homogenizer at $1000 \mathrm{rpm}$ for 180 seconds. The resulted single emulsion was kept for $3 \mathrm{~h}$ under a magnetic stirrer to ensure the complete evaporation of the solvents. CBZ-loaded microparticles were collected by filtration and washed with distilled water three times followed by oven drying $[15,16]$.

\section{Solution preparation}

A quantity of $0.01 \mathrm{~g}$ of carbamazepine (CBZ) weighed accurately and transferred to $10 \mathrm{ml}$ volumetric flask, $2 \mathrm{ml}$ of methanol was added to dissolve CBZ then diluted up to the mark with distilled water. The solution was then filtered utilizing Whatman filter paper No.1 and used as a stock standard solution. To prepare test solution, an amount of CBZ-loaded microparticles equivalent to $0.022 \mathrm{~g}$ of CBZ was weighed in a $100 \mathrm{ml}$ volumetric flask then dissolved in a $15 \mathrm{ml}$ of methanol and diluted with distilled water up to the mark then filtered with Whatman filter paper No.1.

\section{Spectrophotometric method validation}

The spectrophotometric method was validated as per International Conference on Harmonisation (ICH) Q2 guideline. 


\section{Specificity and solution stability}

Specificity was calculated and confirmed by the comparison of carbamazepine (CBZ) ultra-violate (UV) spectrum, ethyl cellulose (EC) UV spectrum, and polyvinyl alcohol (PVA) UV spectrum. CBZ standard solution of $10 \mu \mathrm{g} / \mathrm{ml}$ was prepared and scanned utilizing double beam UV spectrophotometer at a wavelength ranged from 400-200 nm (UV1800 , Shimadzu, Japan). EC solution was prepared by the dissolving of $0.5 \mathrm{~g} \mathrm{EC}$ powder in $90 \mathrm{ml}$ dichloromethane (DCM) under continuous stirring, then $10 \mathrm{ml}$ of ethyl acetate solvent was added to produce $0.5 \%$ of EC solution. PVA solution was prepared by dissolving $0.5 \mathrm{~g}$ of PVA in $100 \mathrm{ml}$ distilled water with heating.

The maximum wavelength of CBZ was selected after scanning and no absorption of the excipients was detected at the same wave length. This wavelength was found to be $286 \mathrm{~nm}$ (fig. 1). Solution stability was evaluated by measuring the absorbance $\left(A_{286}\right)$ of the CBZ solutions at $37^{\circ} \mathrm{C}$ prepared from the standard solution in triplicate $(n=3)$ at different intervals $0,1,3,6,12$, and $24 \mathrm{~h}[17,18]$.

\section{Linearity}

Linearity was evaluated with six different concentrations ranged from $2-12 \mu \mathrm{g} / \mathrm{ml}$ which obtained by diluting of carbamazepine (CBZ) stock solution with distilled water. The linearity of CBZ equation was used to calculate CBZ in the fabricated microparticles [19].

\section{Accuracy}

The accuracy was measured by calculating the recovery of known amounts of carbamazepine (CBZ) added into the dilution medium (distilled water). Three concentrations were examined in triplicate, namely $17.6 \mathrm{mg} / \mathrm{ml}, 22 \mathrm{mg} / \mathrm{ml}$ and $30.8 \mathrm{mg} / \mathrm{ml}$ representing $80 \%$, $100 \%$ and $120 \%$ respectively of the original concentration used in the preparation of CBZ microparticles [20-22].

\section{Precision}

Precision was calculated by measuring nine equalled carbamazepine (CBZ) concentrations $(22 \mathrm{mg} / \mathrm{ml}$ ) prepared from a standard solution of CBZ. Intermediate precision was confirmed by repeating the above step on another day with a different analyst. The relative standard deviation (\% RSD) was then calculated [23-26].

\section{RESULTS AND DISCUSSION}

Developing of a new spectroscopic method for the estimation of drugs in its dosage forms has raised recently due to its important role in pharmaceutical analysis and development [27] Carbamazepine (CBZ) wave length was selected at $286 \mathrm{~nm}$ [28] $\left(\lambda_{\max }=286 \mathrm{~nm}\right.$, fig. 1), whereas no absorption was detected for ethyl cellulose (EC) and polyvinyl alcohol (PVA) excipients at CBZ wavelength. This shows that no interference from the excipients at the selected wavelength $[29,30]$.
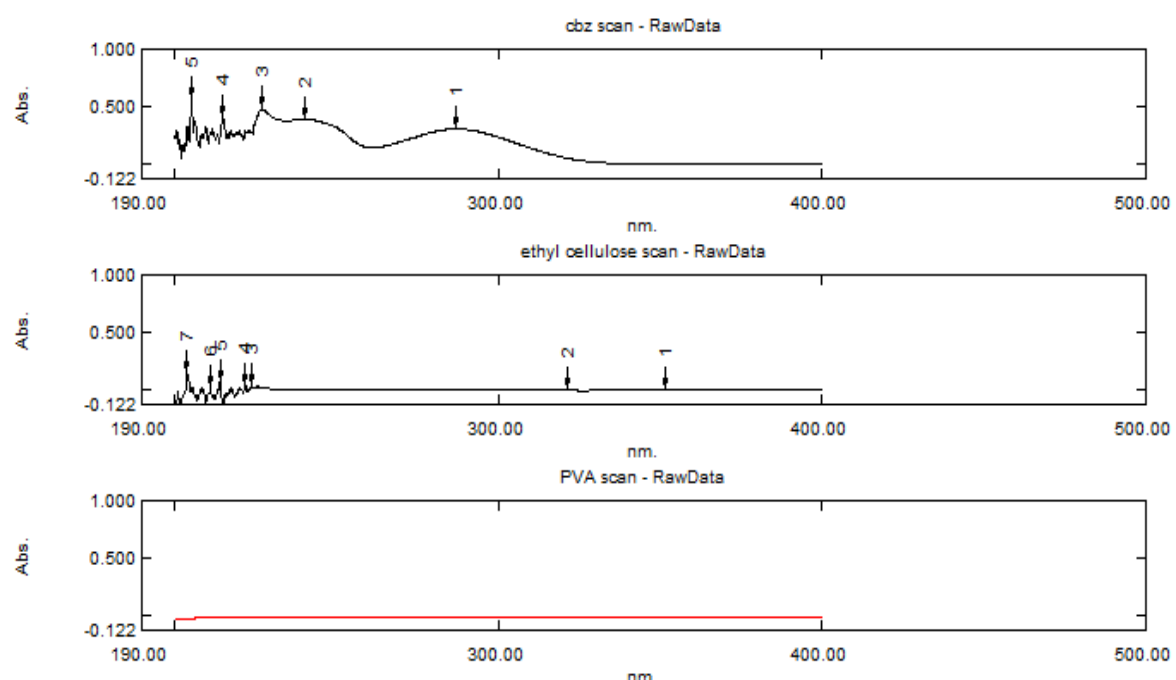

Fig. 1: UV-spectrum of carbamazepine (cbz), ethyl cellulose and polyvinyl alcohol (PVA)

Solution stability study revealed that the absorbance of CBZ was $99 \%$ to $100 \%$ of the initial value (table 1 ) with $\%$ RSD of 0.144 which indicating that the CBZ solution in the water was stable for at least
$24 \mathrm{~h}$. Solution stability is an important criterion to ensure that the prepared samples were stable and no changes could affect the samples during the test period [31].

Table 1: Solution stability of carbamazepine in water

\begin{tabular}{llll}
\hline No. & Time interval (h) & A286 & \% of initial A286 \\
\hline 1 & 0 & 0.579 & 99.80285 \\
2 & 1 & 0.58 & 99.97527 \\
3 & 3 & 0.579 & 99.80285 \\
4 & 6 & 0.579 & 99.80285 \\
5 & 12 & 0.579 & 99.80285 \\
6 & 24 & 0.581 & 100.1477 \\
\hline
\end{tabular}

Mean $=0.580, S D=0.0008, \% \mathrm{RSD}=0.144$. Number of experiments $(\mathrm{n})=3$.

Linearity was calculated using six different concentrations from 2-12 $\mu \mathrm{g} / \mathrm{ml}$. The regression line correlation coefficient $\left(\mathrm{R}^{2}\right)$ was calculated and found to be 0.9992 with ay-intercept of 0.0005 . The slope of the linearity was 0.0526 (fig. 2). These data showed linear absorbance readings through the selected range [32]. The same $\mathrm{R}^{2}$ was found by Kumar et al. for the determination of benidipine hydrochloride in its dosage-forms by using UV-vis spectroscopic method [33].
The recovery of the spiked CBZ added to the medium at $80 \% .100 \%$ and $120 \%$ levels found to be $99.81 \%, 101.33 \%$ and $(99.62 \%)$ respectively, with the relative standard deviation (\% RSD) less than $2(0.97,0.35$ and 0.14 respectively, table 2$)$. This indicates that the method was passed the accuracy test [34].

The results of the precision test are shown in table 3 . The $\%$ RSD was found to be 0.41 for the intraday and 0.36 for the interday indicating that the 
precision values of the validated method were within the accepted limits [35]. The above-validated method was a simple, rapid, precise, accurate and can be used for the estimation of CBZ in the prepared microparticles utilizing the same wavelength and same dose for $24 \mathrm{~h}$ [36].

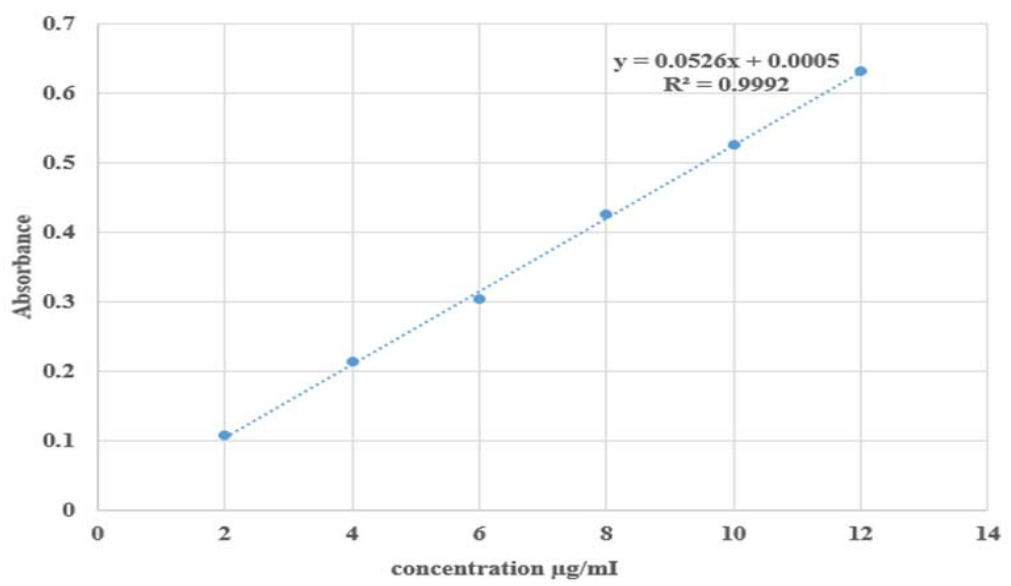

Fig. 2: Linearity curve of carbamazepine in distilled water

Table 2: Accuracy study of carbamazepine spiked at different concentrations.

\begin{tabular}{lllll}
\hline Recovery level & \% recovery & Mean \% recovery & SD & \% RSD \\
\hline $80 \%$ & 100.78 & 99.81 & 0.96 & 0.97 \\
& 99.81 & & & \\
$100 \%$ & 98.84 & 101.33 & 0.36 & \\
& 102.33 & & & \\
$120 \%$ & 101.47 & & 0.14 & 0.14 \\
& 100.18 & 99.62 & & \\
\hline
\end{tabular}

$\mathrm{N}$ (number of experiments) $=3$

Table 3: Results of a precision study of carbamazepine at $100 \%$ concentration level

\begin{tabular}{|c|c|c|}
\hline \multirow[t]{2}{*}{ No. } & \multicolumn{2}{|l|}{ \% Assay } \\
\hline & Intraday & Interday \\
\hline 1 & 99.00 & 98.62 \\
\hline 2 & 98.62 & 98.62 \\
\hline 3 & 98.62 & 98.62 \\
\hline 4 & 99.38 & 99.38 \\
\hline 5 & 99.77 & 99.38 \\
\hline 6 & 99.00 & 99.00 \\
\hline 7 & 99.00 & 98.62 \\
\hline 8 & 98.62 & 99.00 \\
\hline 9 & 99.38 & 99.38 \\
\hline Mean & 99.04 & 98.96 \\
\hline
\end{tabular}

$\mathrm{SD}=0.40$ (intraday) and $=0.36$ (interday). $\% \mathrm{RSD}=0.41$ (intraday), $\% \mathrm{RSD}=0.36$ (interday). Number of experiments $(\mathrm{n})=9$.

\section{CONCLUSION}

In this study, a new UV-Vis spectrophotometric method was developed and validated to quantify CBZ in EC microparticles as per ICH Q2 guideline. The validated method was found to be linear, accurate, precise, and stable for $24 \mathrm{~h}$. Therefore, this method can be used for quantification analysis of CBZ in CBZ-loaded microparticles and can be utilized also as an alternative method to calculate CBZ in different dosage forms.

\section{ACKNOWLEDGEMENT}

This work was funded by IIUM Research Initiative Grant Scheme (Grant Number. RIGS15-092-0092 and Grant no. RIGS16-1140278).

\section{AUTHORS CONTRIBUTIONS}

All the author have contributed equally

\section{CONFLICT OF INTERESTS}

Declared none

\section{REFERENCES}

1. S. Gorog, Ultraviolet-visible spectrophotometry in pharmaceutical analysis: application of UV-VIS spectroscopy in pharmaceutical, CRC; 1995.

2. A Mehta. Ultraviolet-visible (UV-Vis) spectroscopy-derivation of beer-lambert law. Analytical Chemistry; 2012. Available form: pharmaxchange.info. [Last accessed on $20 \mathrm{Feb} 2018$ ]

3. W Kemp. Organic spectroscopy. Molecules 1991;71:11.

4. DG Watson. Pharmaceutical analysis E-book: a textbook for pharmacy students and pharmaceutical chemists, Elsevier Health Sciences; 2015.

5. L Kocsis, P Herman, A Eke. The modified beer-lambert law revisited. Phys Med Biol 2006;515:N91. 
6. A Sassaroli, S Fantini. Comment on the modified beerlambert law for scattering media. Phys Med Biol 2004;4914:N255.

7. R Paynter. Modification of the beer-lambert equation for application to concentration gradients. Surf Interface Anal 1981;34:186-7.

8. D Richard, J Mycek, R Harvey, P Champe. Lippincott's illustrated reviews: pharmacology. Philadelphia 2006;3:413-5.

9. A. S. o. H.-S. P. Wolters kluwer health, cerner multum and micromedex from truven health, Carbamazepine; 2018. Available from: https://www.drugs.com/cdi/carbamazepine.html. [Last accessed on 20 Feb 2018].

10. Z Rezaei, B Hemmateenejad, S Khabnadideh, M Gorgin. Simultaneous spectrophotometric determination of carbamazepine and phenytoin in serum by PLS regression and comparison with HPLC. Talanta 2005;651:21-8.

11. A Serralheiro, G Alves, A Fortuna, M Rocha, A Falcao. First HPLC-UV method for rapid and simultaneous quantification of phenobarbital, primidone, phenytoin, carbamazepine, carbamazepine-10, 11-epoxide, 10, 11-trans-dihydroxy-10, 11dihydrocarbamazepine, lamotrigine, oxcarbazepine and licarbazepine in human plasma. J Chromatogr B 2013;925:1-9.

12. S Mennickent, R Fierro, M Vega, M de Diego, CG Godoy. Instrumental planar chromatographic method for determination of carbamazepine in human serum. J Sep Sci 2009;329:1454-8.

13. USP, Carbamazepine Extended-Release Tablets; 2016. p. 2917-21.

14. WJ Duncanson, T Lin, AR Abate, S Seiffert, RK Shah, DA Weitz Microfluidic synthesis of advanced microparticles for encapsulation and controlled release. Lab Chip 2012;1212:2135-45

15. G Rassu, E Gavini, G Spada, P Giunchedi, S Marceddu. Ketoprofen spray-dried microspheres based on Eudragit ${ }^{\circledR}$ RS and RL: study of the manufacturing parameters. Drug Dev Ind Pharm 2008;3411:1178-87.

16. TW Chung, YY Huang, YZ Liu. Effects of the rate of solvent evaporation on the characteristics of drug loaded PLLA and PDLLA microspheres. Int J Pharm 2001;2122:161-9.

17. M Bakshi, S Singh. Development of validated stabilityindicating assay methods-critical review. J Pharm Biomed Anal 2002;286:1011-40.

18. ISV Aditya, A Kulkarni. Flow injection analysis: an overview. J Crit Rev 2015;2:19-24.

19. L Wang, M Asgharnejad. Second-derivative UV spectrometric determination of simvastatin in its tablet dosage form. J Pharm Biomed Anal 2000;216:1243-8.

20. Y Mehmood, A Tariq, U Jamshaid, M Jumshaid. UV-visible spectrophotometric method development and validation of assay of Iron sucrose injection. Int J Pure Appl Biosci 2015;32:41-53.

21. SJR Charu, P Pandya. Development and validation of stability indicating method rp-hplc methodof acotiamide. Int J Pharm Pharm Sci 2018;10:1-8.
22. NS Sukhbir Singh, Yash Paul Singla, Sandeep Arora Development and validation of uv-spectrophotometric method for quantitative estimation of nefopam hydrochloride in polymethacrylate nanospheres. Int J Pharm Pharm Sci 2016;8:414-9

23. SV Kapakayala, G Mubeen, R Kimbahune. Reverse phase-high performance liquid chromatographic method for quantitation of epinastine hydrochloride in eye drops. Indo Am J Pharm Res 2013;39:7541-8.

24. SSS Hayam, M Lotfy. Recent development in ultraviolet spectrophotometry through the last decade (2006-2016): a review. Int J Pharm Pharm Sci 2016;8:40-6.

25. SB Ashok Chakravarthy A, Praveen Kumar V. Method development and validation of ultraviolet-visible spectroscopic method for the estimation of hepatitis-c drugs-daclatasvir and sofosbuvir in active pharmaceutical ingredient form. Asian J Pharm Clin Res 2016;9:61-6.

26. PS Kalpesh, V Sonar, Anil Jadhav, Tushar Deshmukh, Swapnil Patil, Pallavi Murkute. Development and validation of uv spectroscopic method for estimation of lamivudine in tablet dosage form. Int J Curr Pharm Res 2017;9:86-9.

27. GC Gomes, HRN Salgado. Validation of UV spectrophotometric method for determination of lomefloxacin in pharmaceutical dosage form. Acta Farm Bonaerense 2005;243:406.

28. M Barzegar Jalali, H Valizadeh, S Dastmalchi, M Siahi Shadbad, A Barzegar-Jalali, et al. Enhancing dissolution rate of carbamazepine via cogrinding with crospovidone and hydroxypropylmethylcellulose. Int J Phytother Res 2010;6:159-65.

29. A Biswas, J Sahoo, M Chatli. A simple UV-Vis spectrophotometric method for determination of $\beta$-carotene content in raw carrot, sweet potato and supplemented chicken meat nuggets. LWT-Food Sci Technol 2011;448:1809-13.

30. OC Lastra, IG Lemus, HJ Sanchez, RF Perez. Development and validation of an UV derivative spectrophotometric determination of losartan potassium in tablets. J Pharm Biomed Anal 2003;332:175-80.

31. VP Shah, KK Midha, JW Findlay, HM Hill, JD Hulse, IJ McGilveray, et al. Bioanalytical method validation-a revisit with a decade of progress. Pharm Res 2000;1712:1551-7.

32. G Carr, J Wahlich. A practical approach to method validation in pharmaceutical analysis. J Pharm Biomed Anal 1990;88-12:613-8.

33. AKS Manish Kumar, Ram Singh Bishnoi, CP Jain. Development of uv spectrophotometric method for the determination of benidipine hydrochloride by using quality by design (qbd) approach. Int J Appl Pharm 2018;10:92-7.

34. FT Peters, OH Drummer, F Musshoff. Validation of new methods. Forensic Sci Int 2007;1652:216-24.

35. J Ermer, JHM Miller. Method validation in pharmaceutical analysis: a guide to best practice. John Wiley and Sons; 2006.

36. P Pathade, M Imran, V Bairagi, Y Ahire. Development and validation of stability indicating UV spectrophotometric method for the estimation of sitagliptin phosphate in bulk and tablet dosage form. J Pharm Res 2011;43:871-3. 